\title{
Pigmented mammary paget's disease mimicking melanoma in male patients: A case report and review of the literature
}

\author{
Ahmet Rencüzoğulları ${ }^{1}$, Alexis K. Okoh ${ }^{2}$, Orçun Yalavi ${ }^{1}$, Arbil Acıkalın ${ }^{3}$, Gurhan Sakman ${ }^{1}$, Kubilay \\ Dalci $^{1}$, Suzan Zorludemir ${ }^{3}$
}

1. Cukurova University School of Medicine, Department of General Surgery, Adana, Turkey. 2. Endocrine and Metabolism Institute, Cleveland Clinic, Cleveland Ohio, USA. 3. Cukurova University School of Medicine, Department of Pathology, Adana, Turkey.

Correspondence: Alexis K. Okoh. Address: Endocrine and Metabolism Institute Cleveland $\mathrm{Clinic}, \mathrm{Cleveland} \mathrm{OH}, 9500$ USA. E-mail: disciple951@gmail.com

Received: June 2, 2015

DOI: $10.5430 /$ crcp.v2n4p41
Accepted: July 7, 2015

URL: http://dx.doi.org/10.5430/crcp.v2n4p41

\section{Abstract}

Background: Pigmented mammary Paget's disease (PMPD) of the male breast is extremely rare, and only few cases have been reported to date. Due to the scarcity of the disease, diagnosis as well as treatment is usually delayed. Men tend to present with earlier symptoms, nevertheless, prognosis is known to be worse, with only $20 \%$ to $30 \%$ of the patients surviving over a five year period.

Methods: A case report of a 47-year-old male who presented with a chronic pigmented lesion on the nipple that was later on diagnosed as PMPD.

Results: Microscopic pathological evaluation of mastectomy specimen of the nipple revealed invasive ductal carcinoma Grade II and in situ ductal carcinoma. Estrogen and progesterone receptors were 95\% and 80\% positive for tumor cells. Atypical cells stained positivite for anticytokeratin 7, c-erbB-2, and CEA on immunohistochemistry while cytoplasmic dusty melanin pigments stained focally positive for S-100 and HMB-45.

Conclusion: Although being a rare entity; PMPD should always be kept in mind as a differential diagnosis in melanocytic lesions of the nipple. Histopathology including immunohistochemical staining should always be performed for the correct diagnosis and management.

\section{Key words}

Pagets disease, Male, Breast, Melanoma

\section{Introduction}

Mammary Pagets Disease (MPD), first described by Sir James Paget in $1874{ }^{[1]}$, is a rare clinical entity characterized by eczematous skin lesions of the nipple and usually associated with an underlying breast malignancy. Histologically, the neoplastic cells seen in the epidermis of the skin are most often associated with an underlying ductal carcinoma in situ (DCIS) and/or invasive ductal cancer ${ }^{[2]}$. Male breast cancer is seen in only $1 \%-3 \%$ of all breast malignancies and 
Paget's disease is an uncommon subset. A rare clinicopathologic variant of MPD is PMPD which may clinically and histopathologically mimic malignant melanoma. It was first described by Azzopardi and Eusebi who suggested its association with mammary carcinoma in 1977. Later on Peison and Benisch reported the first histologically confirmed case. Since there have been other cases describing various mechanisms responsible for the clinical pigmentation occasionally observed in PMPD ${ }^{[3,4]}$.

The diagnostic challenge PMPD poses to attending physicians is well known, and with the increasing number of cases in male patients the need to address this confusing clinical entity has arisen. Various underlying mechanisms and risk factors have been proposed ${ }^{[4-7]}$, however, a consensus on an existing association between PMPD and the male population or appropriate treatment methods hasn't been reached yet. To date, there haven’t been any studies objectively comparing treatment protocols in the male population. The definitive treatment of choice however has been radical mastectomy. Current treatment methods such as breast conserving treatment has been widely accepted and recognized. Herein, we present a case of a male patient who presented with a chronic pigmented lesion on the nipple that was later on diagnosed as PMPD. The current literature is reviewed and existing clinical challenges in the diagnosis and management of male patients with PMPD are discussed.

\section{Case presentation}

A 47-year-old male construction worker presented with an itching and bleeding pigmented lesion over his left nipple. His nipple had become discolored, indurated and pruritic for the past 5 months. He had previously been treated for eczema with topical corticosteroids and antifungals for two months without success. Previous personal history of immunosuppression or exposure to chemicals or radiation predisposing to carcinogenesis and family history of skin and breast cancer were unremarkable. Physical examination revealed a $1 \mathrm{~cm} \times 2 \mathrm{~cm}$, scaly, indurated plaque obscuring the normal architecture of the left nipple. Axillary lymph nodes were non palpable and the breast examination including the nipples was normal. Blood discharge from the nipple was noted. All other physical examination findings were unremarkable.

Ultrasonographic imaging of the breast and axilla regions revealed a 4-mm solid lesion in the retroareolar localization but no pathologically enlarged axillary lymph nodes. Sentinel lymph node biopsy did not show metastasis.

A tru-cut biopsy of the retroarealar region revealed G II invasive ductal carcinoma (see Figure 1). The patient underwent mastectomy with sentinel lymph node biopsy which was reported as micrometastasis on peroperative frozen section. Microscopic pathological evaluation of mastectomy specimen was consistent with invasive ductal carcinoma Grade II and in situ ductal carcinoma. Estrogen and progesterone receptors were $95 \%$ and $80 \%$ positive for tumor cells, subsequently.

The areola and nipple samples revealed pleomorphic malignant epitheloid cells with hyperchromatic nuclei, arranged in nested pattern or singularly throughout the epidermis with some cells containing dusty granular melanin pigments. There was an increased number of melanophages in the dermal stroma (see Figure 2a, 2b).

On immunohistochemistry, the atypical cells stained positivite for anticytokeratin 7, c-erbB-2 and CEA (see Figure 2c). Cells with cytoplasmic dusty melanin pigments stained focally positive for S-100 and HMB-45 (see Figure 2d). The melanocytic dendritic cells that were located peripherally to the tumor cells and dermal macrophage cells were strong positive for Melan A and HMB45. As an adjunct to malanoma diagnosis, nuclear cycline D1 positivity was observed in about 70\% of Paget cells. Based on these histopathologic and immunohistochemical findings, a final diagnosis of invasive ductal and in situ ductal carcinoma with pigmented mammary Paget’s disease was made.

Surgery was uneventful and the patient received adjuvant endocrine (due to positive estrogen and progesterone receptors) and radiotherapy as follow up treatment. He is currently in his 15 month of follow-up with no evidence of recurrence. 
Figure 1. Gross examination of mastectomy specimen reveals pigmentary changes in the nipple (long arrow) and ductal carcinoma (short arrow) focus under areola
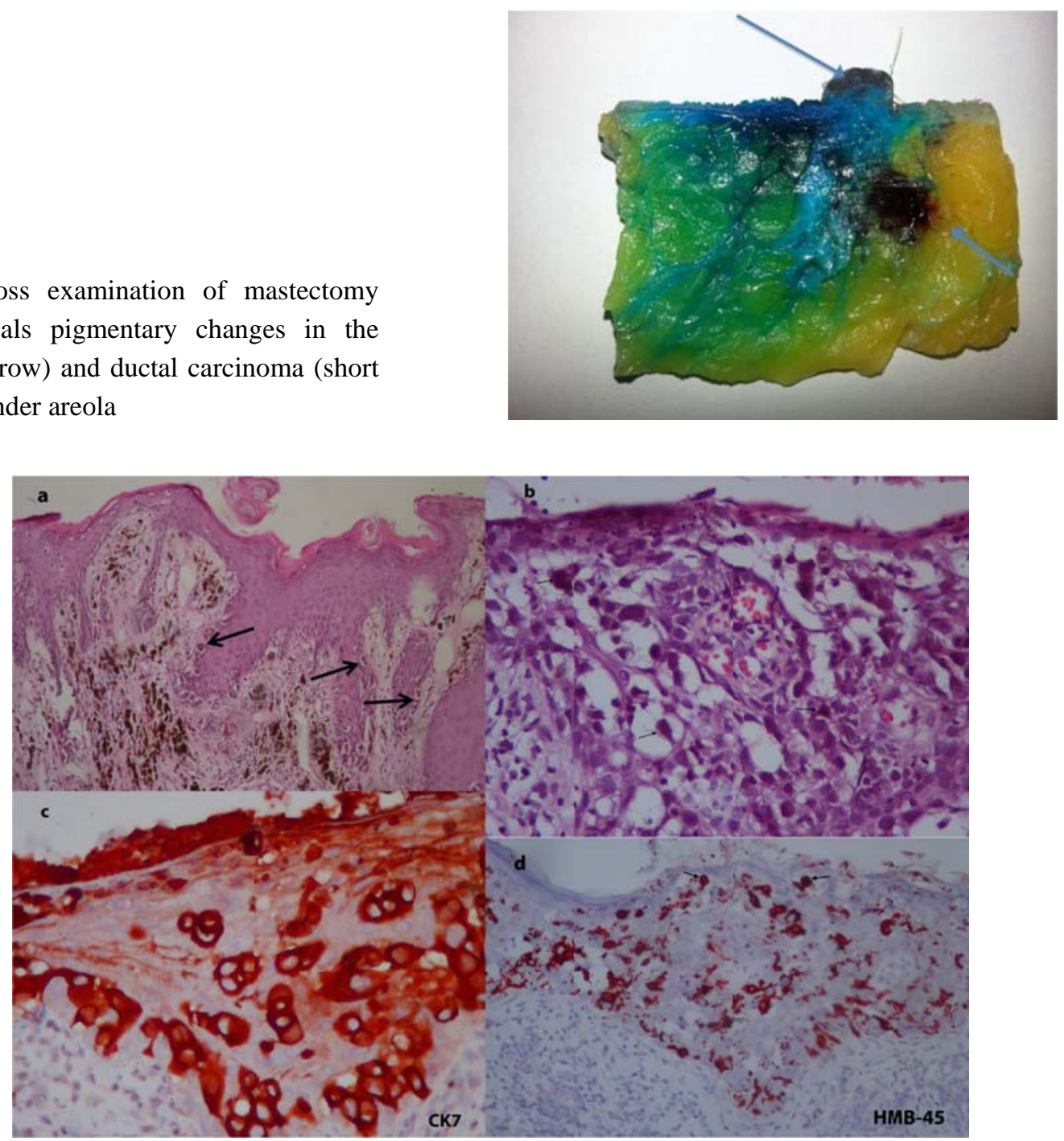

Figure 2. a: Malignant epitheloid cells with hyperchromatic nuclei singularly arranged in epidermis are present (arrows) (HE, $\times 100)$. b: Dusty melanin pigment is present in cytoplasms of some cells (arrows) (HE, $\times 400$ ). c: Cytokeratin 7 positivity in atypical cells (IHC, $\times 400$ ). d: HMB45 positivity in pigmented cells (IHC, $\times 200$ ).

\section{Discussion}

Paget's disease of the breast is usually nonpigmented and occurs almost always in women. Paget's disease of the breast in males is extremely rare and few cases were reported in the literature. PMPD was first described in 1990 as a rare clinicopathological variant of MPD associated with intraductal mammary carcinoma or of invasive mammary carcinoma, extending up the nipple and areola epidermis ${ }^{[8]}$. The problem of this entity is the difficulty of distinguishing PMPD from melanoma clinically and histopathologically.

Although both PMPD and melanoma need to be surgically excised, surgical and postoperative management of the two are different. MPD and PMPD usually have an underlying invasive or in situ breast cancer; however there may not be an associating underlying cancer in few cases. Once the diagnosis of MPD or PMPD is made, an underlying breast cancer should be eliminated since the treatment is based on the underlying pathology. In pure PMPD or MPD, total mastectomy has been the standard treatment but recent reports suggested that breast conserving surgery in selected cases could be the treatment of choice with similar survival rates ${ }^{[9,10]}$. However, in cases treated with breast conserving surgery, surgical margins should be assessed intraoperatively after ruling out an underlying breast cancer. 
In our case we performed mastectomy with sentinel lymph node biopsy because both physical examination and ultrasonography did not reveal pathologically enlarged lymph nodes. Interestingly, the result showed micrometastasis of an underlying breast cancer. According to the current literature, the decision to perform axilla lymph node dissection (ALND) or not as treatment for micrometastasis remains in dispute. Alternatively, radiotherapy or close medical surveillance has been recommended in cases of micrometastasis ${ }^{[11]}$. We did not proceed with ALND but rather preferred a treatment regimen of low dose radiotherapy. By this, the side effects of ALND could be decreased on the patient.

A review of the English medical literature revealed a little over 50 cases of MPD in males reported so far. Out of the cases reported only nine cases were presented as the pigmented variant of mammary Paget's disease ${ }^{[7,8,12,16,19-23]}$. All reported cases of PMPD in men were associated with an underlying breast carcinoma but one (Bernadi et al.). In one case, PMPD was diagnosed in a male previously treated with mammaplasty reduction for gynecomastia (Ho et al.) confirming the diagnostic challenge this entity can pose in clinical practice.

Age, abnormalities in estrogen and androgen balance including testicular diseases (orchiectomy, testicular injury, and congenital hernia), obesity and infertility are among the known risk factors for breast cancer in males. Also, individuals with a positive family history, of Jewish ancestry or diagnosed with Klinifelters syndrmome (47, XXY karyotype), can be genetically predisposed. In the absence of a positive family history, BRCA2 mutations can also predispose men to breast cancer. In the absence of a positive family history, BRCA2 mutations are known to account for $4 \%$ of male breast malignancies ${ }^{[13]}$.

Histological findings from previous studies have reported $90 \%$ of male breast cancers as being invasive, with most being ductal carcinomas. Approximately $80 \%$ are estrogen receptor positive, $75 \%$ progesterone receptor positive and $35 \%$ over express HER2/neu. The remaining $10 \%$ are in situ of the ductal type with $75 \%$ of these being of the papillary subtype. In our case, both estrogen and progesterone receptors are highly positive, which is in agreement with two of the ten cases of PMPD in males reported so far.

Histopathologiocally, Paget's disease is positive for CK7, EMA, CEA, and mucin, whereas negative for Melan A, HMB-45, and S-100 which are positive for melanoma ${ }^{[14]}$. Paget's cells express HER2/neu receptors and c-erb B-2 oncogene which indicate common histological and biological origin with breast carcinoma ${ }^{[10,15]}$. On the other hand Paget's cells contain phagocytosed melanosomes which cause confusion in differentiating them from melanoma cells. Additionally, these cells contain cytoplasmic protein S-100 and HMB-45 just like malignant melanoma as in our case.

Nakamura et al. have reported that the atypical cells were positive for CEA, human-milk fat globule protein and a recently described new antigen, RCAS-1, but negative for S-100 or HMB-45 ${ }^{[16]}$. In Menet et al.'s report; histologically, large Paget's clear cells were intermingled with numerous melanin-rich dendritic melanocytes. After differential immunohistochemical staining, diagnosis of Paget's disease could be unequivocally substantiated since Paget's cells stained for epithelial markers, c-erbB-2 and hormonal receptors, whereas protein S-100 and HMB-45 were negative ${ }^{[18]}$.

At this point CK7 is the most valuable marker in distinguishing malignant melanoma from MPD. CK7 is highly sensitive but not a specific marker for all types of Paget's disease but melanoma cells are negative ${ }^{[15,17]}$. In our case, the presence of HMB-45 and S-100 positive Paget's cells throughout the epidermis was challenging, but the presence of CK 7 positivity led us to an accurate diagnosis.

In conclusion; although being a rare entity; PMPD should always be kept in mind as a differential diagnosis in pigmented lesions of the nipple. It poses a diagnostic dilemma as it is difficult to differentiate from cutaneous melanoma. Histopathology including immunohistochemical staining should always be performed for the correct diagnosis and management. Treatment options depend on the type of cancer and stage of disease. 


\section{Disclosure}

None to declare.

\section{References}

[1] Paget J. On disease of the mammary areola preceding cancer of the mammary gland. St Bartholomew Hosp Res Lond. 1874; 10: 87-9.

[2] Singla V, Virmani V, Nahar U, et al. Paget's disease of breast masquerading as chronic benign eczema. Indian J Cancer. 2009; 46: 344-7. PMid: 19749470. http://dx.doi.org/10.4103/0019-509X.55560

[3] Vielh P, Validire P, Kheirallah S, et al. Paget's disease of the nipple without clinically and radiologically detectable breast tumor. Histochemical and immunohistochemical study of 44 cases. Pathol Res Pract. 1993; 189: 150-5. http://dx.doi.org/10.1016/S0344-0338(11)80085-3

[4] Peison B, Benisch B. Paget’s disease of the nipple simulating malignant melanoma in a black woman. Am J Dermatopathol. 1985; 7(Suppl): 165-9. PMid: 2856457. http://dx.doi.org/10.1097/00000372-198501001-00031

[5] O’Sullivan ST, McGreal GT, Lyons A, et al. Paget's disease of the breast in a man without underlying breast carcinoma. J ClinPathol. 1994; 47(9): 851-2. PMid: 7962657. http://dx.doi.org/10.1136/jcp.47.9.851

[6] Serour F, Birkenfeld S, Amsterdam E, et al. Paget’s disease of the male breast. Cancer. 1988; 62(3): 601-5. http://dx.doi.org/10.1002/1097-0142(19880801)62:3<601::AID-CNCR2820620326>3.0.CO;2-7

[7] Fredrik Petersson, Doina Ivan, Dmitry V, et al. Pigmented Paget Disease - A Diagnostic Pitfall Mimicking Melanoma. Am J Dermatopathol. 2009; 31: 223-6. PMid: 19384061. http://dx.doi.org/10.1097/DAD.0b013e3181930dc6

[8] Ho TC, St Jacques M, Schopflocher P. Pigmented Paget's disease of the male breast. J Am Acad Dermatol. 1990. http://dx.doi.org/10.1016/0190-9622(90)70217-6

[9] Dalberg K, Hellborg H, Wärnberg F. Paget's disease of the nipple in a population based cohort. Breast Cancer Res Treat 2008; 111: 313-9 Hilliard NJ, Huang C, Andea A. Pigmented extramammary Paget's disease of the axilla mimicking melanoma: case report and review of the literature. J Cutan Pathol. 2009 Sep; 36(9): 995-1000.

[10] Hida T, Yoneta A, Nishizaka T, et al. Pigmented mammary Paget's disease mimicking melanoma: report of three cases. Eur J Dermatol. 2012 Jan-Feb; 22(1): 121-4. PMid: 22064040.

[11] Abreu EB, Martinez P, Betancourt L, et al. Treatment plan for breast cancer with sentinel node metastasis. E cancer medical science. 2014 Jan 8; 8: 383. eCollection 2014.

[12] Mike Bernardi, Alia Sampson Brown, Janine C. Malone, et al. Paget Disease in a Man Arch Dermatol. 2008; 144(12): 1660-2.

[13] Iglehart DJ, Kaelin CM. Diseases of the breast. In: Towsend CM, Beauchamp RD, Evers BM, Mattox KL, editors. Textbook of surgery.17th ed. London: WB Saunders; 2004. 867-928p.

[14] Petersson F, Ivan D, Kazakov DV, et al. Pigmented Paget disease-a diagnostic pitfall mimicking melanoma. Am J Dermatopathol. 2009; 31: 223-6. PMid: 19384061. http://dx.doi.org/10.1097/DAD.0b013e3181930dc6

[15] Feinmesser M, Veltman V, Morgenstern S, et al. Different patterns of expression of the erbB family of receptor tyrosine kinases in common nevi, dysplastic nevi, and primary malignant melanomas: an immunohistochemical study. Am J Dermatopathol. 2010; 32: 665-75. PMid: 20559114. http://dx.doi.org/10.1097/DAD.0b013e3181d1e6f0

[16] Nakamura S, Ishida-Yamamoto A, Takahashi H, et al. Pigmented Paget's disease of the male breast: report of a case. Dermatology. 2001; 202: 134-7. PMid: 11306836. http://dx.doi.org/10.1159/000051614

[17] Fujisawa Y, Yamamoto A, Machida H, et al. Cytokeratin 7 staining was useful in a case of pigmented mammary Paget's disease resembling malignant melanoma. Int J Dermatol. 2006; 45: 1257-8. PMid: 17040462. http://dx.doi.org/10.1111/j.1365-4632.2006.03015.x

[18] Menet E, Vabres P, Brecheteau P, et al. Pigmented Paget's disease of the male nipple. Ann Dermatol Venereol. $2001 ; 128: 649-52$. PMid: 11427802.

[19] Mitchell S, Lachica R, Randall MB, et al. Paget's disease of the breast areola mimicking cutaneous melanoma. Breast J. 2006; 12: 233-6. PMid: 16684321. http://dx.doi.org/10.1111/j.1075-122X.2006.00247.x

[20] Stretch JR, Denton KJ, Millard PR, et al. Paget's disease of the male breast clinically and histopathologically mimicking melanoma. Histopathology. 1991; 19: 470-2. PMid: 1661703. http://dx.doi.org/10.1111/j.1365-2559.1991.tb00240.x

[21] Pimentel CL, Barnadas MA, Dalmau J, et al. Pigmented Paget's disease in a man previously treated with mammaplasty reduction for gynecomastia. J Am AcadDermatol. 2006; 55: S62-3. PMid: 16843133. http://dx.doi.org/10.1016/j.jaad.2006.02.044

[22] ZeglaouiFaten, Khaled Aida, FazaaBecima, et al. Pigmented Mammary Paget's Disease Mimicking Melanoma a Further Case in a Man. The Breast Journal. 2009; 15(4): 420-1. PMid: 19470138. http://dx.doi.org/10.1111/j.1524-4741.2009.00750.x

[23] Celia Chao, Michael J. Edwards, Stewart Wolfson, et al. Paget's Disease of the Male Breast: An Unusual Case of Dermal Invasion. The Breast Journal. 2003; 9(3): 254. PMid: 12752641. http://dx.doi.org/10.1046/j.1524-4741.2003.09317.x 